\title{
Which Kantian Conceptualism (or Nonconceptualism)?
}

\section{By Kevin Connolly}

\begin{abstract}
A recent debate in Kant scholarship concerns the role of concepts in Kant's theory of perception. Roughly, proponents of a conceptualist interpretation argue that for Kant, the possession of concepts is a prior condition for perception, while nonconceptualist interpreters deny this. The debate has two parts. One part concerns whether possessing empirical concepts is a prior condition for having empirical intuitions. A second part concerns whether Kant allows empirical intuitions without a priori concepts. Outside of Kant interpretation, the contemporary debate about Conceptualism concerns whether perception requires empirical concepts. But, as I argue, the debate about whether Kant allows intuitions without empirical concepts does not show whether Kant is a conceptualist. Even if Kant allows intuitions without empirical concepts, it could still be a priori concepts are required. While the debate could show that Kant is a conceptualist, I argue it does not. Finally, I sketch a novel way that the conceptualist interpreter might win the debate: roughly, by arguing that possessing a priori concepts is a prior condition for having appearances.
\end{abstract}

\section{Introduction}

A recent debate in Kant scholarship, traversing both the Anglophone and Germanophone literature, focuses on the role that concepts play in Kant's theory of perception. Very roughly, proponents of a nonconceptualist interpretation argue that for Kant, the possession of concepts is not a prior condition for perception. ${ }^{1}$ These proponents include Lucy Allais (2009), Robert Hanna (2005, 2008), and Peter Rohs (2001). On the other side of the debate, Hannah Ginsborg (2006a, 2008), Aaron Griffith (2010), John McDowell (1994), and Christian Helmut Wenzel (2005) claim that Kant is a conceptualist. They argue that on Kant's view, the possession of concepts is a prior condition for perception.

The debate is typically posed in terms of whether Kant allows "empirical intuitions" [empirische Anschauungen] without concepts. (Note that there is some precedent for translating Anschauung as "perception" (see Gram, 1982, p. 42)). John McDowell explains empirical intuitions

\footnotetext{
${ }^{1}$ As defined here, this version of Nonconceptualism is a kind of "State Nonconceptualism," a view recently endorsed and defended by Tim Crane (2008). On this view, one can have a perception that the ball is shiny even if one lacks the concept of shininess. Some have argued that the Conceptualism/Nonconceptualism debate ought not to be about states, but about contents (see Heck, 2000, p. 485, and Speaks, 2005, pp. 359-62). I explain this idea further, and challenge its applicability to this paper's argument in section 4.3.
} 
as "bits of experiential intake" (1994, p. 4). In the following discussion, I will hold a perception to be a bit of experiential intake. My use of "experience" here should not be confused with Kant's cognitive term Erfahrung. On my use of "experience," it is still an open question whether experiential intake requires concepts. The debate about whether Kant is a conceptualist or a nonconceptualist is a debate about whether Kant allows empirical intuitions without concepts, or, to put it another way, whether he allows experiential intake without concepts.

One might suppose that concepts of a bird or a house come to us by way of perception. The idea would be that a child acquires the concept of a bird through perceiving instances of birds. After all, it seems implausible that a child would just be born with that concept. It seems much more likely that the concept of a bird is acquired. But if concepts are acquired through perception, how could perception itself require concepts?

Kant makes a distinction which provides an answer to this question. He distinguishes between empirical concepts and a priori concepts (also known as the categories). Empirical concepts arise from the senses. One acquires them by abstracting common features from several distinct objects of the same kind (“Jäsche Logic," 92). Empirical concepts include the concepts of a bird or a house. Our ordinary intuitions about concepts are correct for empirical concepts, as in the above case of the child and the bird. Those concepts are acquired through perception, and are not required for perception itself. On the other hand, our ordinary intuitions are incorrect when applied to a second class of concepts. Those concepts are a priori concepts, which are general concepts like the concept of unity. Such concepts are not derived from perception.

One part of the debate concerns the relationship between empirical intuitions and empirical concepts, again, the latter include the concepts of a bird or a house, which come to us by way of the senses through a process of abstracting common features from several distinct objects of 
experience ("Jäsche Logic," 92). The debate here is whether Kant allows empirical intuitions without empirical concepts. Nonconceptualist interpretations claim that Kant does allow them, while conceptualist interpretations claim he does not.

The second part of the debate concerns the relationship between empirical intuitions and a priori concepts. The issue here is whether Kant allows perception without a priori concepts. Nonconceptualist interpretations claim that Kant allows them, while conceptualist interpretations claim he does not.

The novel contribution of this paper is in showing that the first part of the debate is misguided. The contemporary debate about Conceptualism (outside of Kant interpretation) concerns whether perception requires what Kant would call "empirical concepts" (although cf. Smith, 2002, p. 119). But the debate about whether Kant allows intuitions without empirical concepts does not show whether Kant is a conceptualist. In fact, for the nonconceptualist, the debate cannot show that Kant is a nonconceptualist. After all, even if Kant allows intuitions without empirical concepts, it does not follow that he allows intuitions without concepts simpliciter. It could still be that for Kant, a priori concepts are prior conditions for perception. For the conceptualist interpreter, the debate about whether Kant allows intuitions without empirical concepts can show that Kant is a conceptualist. But as I will argue, it does not.

In section 2.1 and 2.2, I evaluate the debate over whether Kant allows empirical intuitions without empirical concepts. In 2.1, I examine the evidence that Kant prohibits empirical intuitions without empirical concepts. In section 2.2, I examine the evidence that Kant allows empirical intuitions without empirical concepts. My claim is that the standard arguments in both directions fail. We have no conclusive reason to think that he allows them, and we have no conclusive reason to think that prohibits them. I then argue that once we see the debate as a question 
about whether Kant allows empirical intuitions without a priori concepts, we have good reason to hold that Kant is a conceptualist.

\section{Empirical Concepts and Perception}

\subsection{The Argument from Blind Intuitions}

One of the most quoted lines from the Critique of Pure Reason is, "Thoughts without content are empty, intuitions without concepts are blind" ( $C P R$ B75). Some take this slogan to support the view that Kant is a conceptualist. They claim that Kant's slogan rules out the possibility of intuitions without concepts.

What does it mean for intuitions without concepts to be blind? In Mind and World, McDowell answers this question as follows. Among other things, it means that a concept of $x$ is a prior condition for a perception (intuition) of $x$. A perception of a body, for instance, requires one to possess the concept of a body. Without that concept, the perception (intuition) would be blind. (One assumption here is that in a perception of a body, a body actually appears to the subject. It is not just that the object he is looking at is a body, regardless of how it appears to him).

\subsubsection{A Reply to McDowell}

As Peter Rohs, Robert Hanna, and Lucy Allais point out, however, just because intuitions without concepts are blind, it does not follow that they do not exist. It could just be that such intuitions do not yield knowledge (see Rohs, 2001, p. 220, Hanna, 2008, p. 45, and Allais, 2009, pp. 392-93). We can generalize this nonconceptualist response. For any claim that Kant makes about the impossibility of intuitions without concepts, nonconceptualists can argue that that claim is restricted to the role of intuitions in the production of knowledge. Call this, the knowledge restriction strategy. 
The knowledge restriction strategy deflates McDowell's argument. The response shows that Kant's slogan alone does not entail conceptualism. After all, when Kant claims "intuitions without concepts are blind," he could just mean that intuitions without concepts are blind in the sense that they do not produce knowledge by themselves. But note the following. Even if "intuitions without concepts are blind" only applies to cognition, it also does not follow that there are intuitions without concepts. Even supposing that Kant does not rule out the existence of intuitions without concepts, it does not follow that that such intuitions exist. Applying this to the debate at hand, even if Kant does not rule out intuitions without concepts, it does not follow that he is a nonconceptualist. So it follows from the slogan neither that Kant is a conceptualist, nor that he is a nonconceptualist. In determining whether Kant is a conceptualist or a nonconceptualist, Kant's slogan is mute. It says nothing either way.

\subsubsection{McDowell's Revised Position}

In his 2008 paper, "Avoiding the Myth of the Given," McDowell revises his position from Mind and World. One major change is in the Kantian slogan that McDowell employs. In Mind and World, he uses Kant's slogan "intuitions without concepts are blind" (CPR B75), and as I have just argued, he draws a conclusion from that slogan that does not follow (at least as an interpretation of Kant). To say that intuitions without concepts are blind is not to say that they do not exist. So Kant's slogan does not show that Kant is a conceptualist.

In “Avoiding the Myth of the Given," however, McDowell uses a second Kantian slogan: "It must be possible [können] for the 'I think' to accompany all my representations" $(C P R$ B131). There is a lot to unpack here, but roughly what the slogan does is put a condition on having intuitions. Intuitions are a kind of representation ( $C P R \mathrm{~B} 93)$. The condition on intuitions is as follows: it must be possible to represent your intuition in the form of a judgment. The "must be 
possible" wording is important. The claim is that even if you do not actually articulate your intuition, that intuition is articulable. That is, every intuition is a potential candidate for a judgment.

McDowell's new view runs as follows. A perception is an intuition. Intuitions have a special character. Specifically, they can be articulated. When we make a judgment about a perception, we are articulating an intuition. This is not to say that we articulate all of our intuitions. But the important point is that our intuitions are articulable, even if we do not actually end up articulating them.

We can enrich McDowell's view by thinking of Kant's claim that objects of experience conform to our cognitive faculty, a conformity that involves multiple levels: space, time, and the categories. Our cognitive faculty is a faculty with a telos, namely, the end of producing a body of knowledge. Kant's slogan, 'It must be possible for the 'I think' to accompany all my representations," is the principle of our cognitive faculty. So McDowell's new view can be read as follows: it must be possible to represent your intuition as a judgment, and this is one step in part of a multi-level process whose end is knowledge. A judgment is something that can be responsive to your other beliefs and can contribute to a body of knowledge.

Notice though that McDowell's new view is actually consistent with a nonconceptualist interpretation of Kant. The nonconceptualist can agree that it must be possible to represent your perception in the form of a judgment. Nonconceptualists already grant the fact that in cases of knowledge, we do represent our perception in the form of a judgment. Nothing prevents them from saying that all experiences are potentially cases of knowledge. Their point is just that there are perceptions that do not become knowledge. Put another way, their point is simply that there are intuitions without concepts. 
On his new view, McDowell himself seems to allow the existence of intuitions without concepts. He admits that for much of the content in an ordinary intuition, we never develop the conceptual capacity to articulate that content. This is the case, he says, with most of the finegrained shades of color and fine-grained shapes in our experience (2008, p. 8). McDowell's point, however, is that just because we do not conceptualize much of the content in an ordinary intuition, it does not mean that we could not do so. His claim is simply that we must be able to conceptualize intuitions, even if we do not actually do so. Once again, this leaves room for the existence of intuitions without concepts. Unconceptualized intuitions would just seem to be intuitions without concepts.

While I think that McDowell's new view is an improvement over his old view (as I see it, it ends up offering a more plausible account of perceptual justification), I think that he does not go far enough to defend his view as a conceptualist view. This is surprising because McDowell could use Kantian resources to do so. He just needs to argue that intuitions require concepts, but that the concepts they require are a priori concepts, not empirical concepts. If McDowell were to take this position, then he could block the possibility of intuitions without concepts.

Reconsider Kant's slogan: “It must be possible for the 'I think' to accompany all my representations" (CPR B131). I said that it means, roughly, that it must be possible for a subject to represent her perception in the form of a judgment, as part of a multi-level process whose end is knowledge. But notice that the slogan itself says nothing about cases where a subject does not represent her experience in the form of a judgment. That is, it says nothing about cases of intuitions without concepts. It does not preclude intuitions without concepts, but it does not endorse their existence either. As with the slogan "intuitions without concepts are blind," in determining whether Kant is a conceptualist or a nonconceptualist, this new slogan says nothing either way. 


\subsection{The Argument from the Immediacy of Intuitions}

Is there other evidence indicating that Kant asserts the existence of intuitions without concepts? Kant says that intuitions relate immediately to objects (CPR B33, B93, and B377). Peter Rohs (2001, p. 214) and Lucy Allais (2009, p. 389) argue that this contrasts with Kant's claim that concepts relate to objects only through mediation (they cite $C P R$ B93 and B377).

In "Bezieht sich nach Kant die Anschauung unmittelbar auf Gegenstände?" [“Do Intuitions Relate Immediately to Objects for Kant?"] Rohs begins by arguing that for Kant, intuitions relate immediately to objects, while concepts do not. He then claims that this motivates a distinction between "seeing something" and "seeing that something is the case" (p. 215). Seeing that something is the case involves empirical concepts, he argues, while merely seeing something does not involve empirical concepts.

Rohs applies this distinction to the case of perceiving an apple. Seeing that something is an apple requires the concept of an apple, while merely seeing an apple does not (p. 219). Rohs claims that when intuitions relate immediately to objects, this is equivalent to "seeing something." When intuitions are coupled with concepts, this is equivalent to "seeing that something is the case." He argues that intuitions without empirical concepts occur in cases where we see something, but do not see that something is the case.

\subsubsection{A Reply to Rohs}

While I accept the distinction between seeing something and seeing that something is the case, I do not think the distinction motivates Rohs' conclusion. Rohs is right that one can see an apple without seeing that it is an apple. However, it doesn't follow that one can see an apple without using any concepts whatsoever (even assuming we restrict ourselves to empirical con- 
cepts). As a counter-example, suppose I see an apple without seeing that it is an apple, but while seeing that it is an object. In one respect, this is a case of merely seeing something. I am just seeing an apple. But in another respect, I am still seeing that something is the case. I am seeing that the apple is an object.

Rohs' mistake is the assumption that just because one can see an apple without possessing the concept of an apple, one can see an apple without possessing any concepts. In other words, he assumes that seeing that it is an apple would be a conceptualization of a nonconceptual state, and not a reconceptualization of a previously conceptual state (see Laurence and Margolis, forthcoming). If you see that it is an apple now, but previously saw that it is an object, however, your new perceptual state would be a reconceptualization of a previously conceptual state.

Rohs cannot just rely on cases like the apple case, where a subject sees an $x$ without seeing that it is an $x$. These cases do not show the possibility of intuitions without empirical concepts. What he needs is a case where a subject sees something without seeing that it is anything. He needs such a case because he needs an example of intuitions without any empirical concepts, not just without one particular empirical concept.

Unfortunately for Rohs, it is difficult to imagine a case where a subject sees something without seeing that it is anything. It is hard to imagine any object that one could see without at least seeing that it is an object. This point is helpful to keep in mind when examining Kant's claims about infants, non-human animals, and so-called "savages" (for further discussion these cases, see Hanna, 2005; Allais, 2009; and McLear, 2011). ${ }^{2}$

Kant writes:

If a savage sees a house from a distance for example, with whose use he is not acquainted, he admittedly has before him in his representation the very same object as

\footnotetext{
| ${ }^{2}$ I thank an anonymous reviewer for pushing me to think more about these claims.
} 
someone else who is acquainted with it determinately as a dwelling established for humans. But as to form, this cognition of one and the same object is different in the two. With one it is mere intuition, with the other it is intuition and concept at the same time. ("Jäsche Logic," 33)

Following Hanna (2005, p. 262), I take Kant's stipulation in this passage to be that the "savage" lacks the concept of a house (or, at least, he does not deploy the concept). But the point I want to raise is this: while the "savage" may have a mere intuition in the sense that his intuition is not accompanied by the concept of a house, it does not follow that he has a mere intuition full stop. After all, his intuition may be accompanied by a different empirical concept, such as the concept of an object. If so, then this would not be a case of an intuition without a concept.

Regarding the case of non-human animals, Hanna writes:

Kant holds that it is possible for non-human animals - e.g. an ox - to have outer sense intuitions of material objects in space - e.g. a barnyard-gate - without any corresponding concepts and indeed without any conceptual capacities whatsoever ("The False Subtlety of the Four Syllogistic Figures," 2: 59). The ox sees the gate, but cannot see the gate as a gate... (2005, p. 262)

Allais references the same passage, saying of Kant, "[W]hile he denies that the ox can see a gate as a gate, he clearly says that it sees the gate" (2009, p. 406). But, again, even if the ox cannot see the gate as a gate, it does not follow that the ox sees the gate as nothing. Again, we might think that even if the ox does not see the gate as a gate, it still sees the gate as an object. ${ }^{3}$

In the case of adult humans, the following point is still more important. Even if there were intuitions without empirical concepts, this does not entail that Kant is a nonconceptualist. Showing that Kant allows intuitions without empirical concepts does not show that Kant allows intuitions without concepts simpliciter. Since Kant holds that there are a priori concepts in addi-

\footnotetext{
${ }^{3}$ Although the line I take can be applied to infants as well, one additional point about infants is this: Kant evidently thinks that they lack perception [Wahrnehmung] for a period of time from birth (Anthropology from a Pragmatic Point of View, 7: 127-128). Note that if infants were to lack intuitions during this period, they would not even be candidates for having intuitions without concepts during that time.
} 
tion to empirical concepts, it could still be that a priori concepts are necessary for intuitions. So, if Kant allows intuitions without empirical concepts, but not without a priori concepts, then he does not actually permit intuitions without concepts. If this is the case, then he is not a nonconceptualist. In short, we could just grant the existence of intuitions without concepts to the nonconceptualist, and nonconceptualism still would not follow.

As it turns out, then, the debate about whether Kant allows intuitions without empirical concepts does not show whether Kant is a conceptualist. In fact, for the nonconceptualist, the debate cannot show that Kant is a nonconceptualist. After all, even if he allows intuitions without empirical concepts, it does not follow that he allows intuitions without concepts simpliciter.

For the conceptualist, on the other hand, the debate about whether Kant allows intuitions without empirical concepts could show that Kant is a conceptualist. If the conceptualist were able to show that Kant denies intuitions without empirical concepts, then that would show that Kant is a conceptualist. But, as I argued, the debate does not show that. McDowell argues for Conceptualism by using Kant's slogan, "intuitions without concepts are blind.” But even if intuitions without concepts are blind, it does not follow that intuitions without concepts do not exist. What's more, McDowell's most recent position not only fails to rule out intuitions without concepts. It seems to endorse their very existence.

The conceptualist interpreter of Kant then has two potential paths to winning the debate. The first path is to show that empirical concepts are prior conditions for perception. The second path is to show that a priori concepts are prior conditions for perception. McDowell takes the first path, but is unsuccessful. But the nonconceptualist needs to block both paths in order to win the debate. After all, even if nonconceptualists block the first path, Kant could still be what A. D. 
Smith refers to as a categorial conceptualist (2002, p. 119). That is, Kant still might hold that the categories are prior conditions for perception.

The upshot of sections 2.1 and 2.2 is the following: the question as to whether Kant is a conceptualist comes down to the question as to whether he allows empirical intuitions without a priori concepts. If he allows empirical intuitions without a priori concepts, then he is a nonconceptualist. If he rejects the possibility of empirical intuitions without a priori concepts, then he is a conceptualist.

Let me make one final qualification, though. Someone might object that the operation of a priori concepts in perception requires the operation of certain empirical concepts. The idea is that in the perceptual apprehension of a house, for instance, the operation of the categories of quantity require the operation of certain empirical concepts. So, the argument continues, the category of plurality cannot be in operation without certain empirical concepts such as the concept of a chimney, a roof, and a door, for instance. ${ }^{4}$

I think that my view can accommodate the bulk of this possibility, as long as I hold two restrictions. First, the empirical concepts allowed must be restricted to a single token concept: the concept of an object. Second, the concept of an object needs to be deployed multiple times. We can allow that the category of plurality requires the deployment of empirical concepts, as long as we hold that it is the same empirical concept (the concept of an object) that we deploy multiple times: once for the chimney, and again for the roof, and a third time for the door, and so on. Nonconceptualist interpreters have not blocked this move. While they have shown that according to Kant, we can see a chimney without seeing it as a chimney, they have not shown that he permits that we can see a chimney without seeing it as an object.

\footnotetext{
${ }^{4}$ I thank an anonymous reviewer for pointing out this possibility to me.
} 


\section{A Priori Concepts and Perception}

\subsection{The Interpretive Problem}

Kant famously argued that objects of experience must conform to the form of our cognitive faculty: to the forms of space and time, and to certain conceptual forms (the categories). Not all of our concepts are derived from experience, he claimed. Rather, the possession of some basic concepts is a prior condition for experience itself. He argued that this insight, along with the insight that objects of experience conform to the forms of space and time, would provide philosophy with a shift in standpoint akin to the Copernican shift in astronomy, and no less important. As he put it:

[Copernicus] tried whether he might not have better success if he made the spectator to revolve and the stars to remain at rest. A similar experiment can be tried in metaphysics... I assume that objects... conform to concepts. (CPR Bxvi-xvii)

According to Kant, this Copernican shift for philosophy could give us both a diagnosis of the past failings of metaphysics and a basis for future metaphysics. Just as many failures of past astronomy are due to ascribing the apparent rotation of the stars to the stars themselves, so too are many failures of past metaphysics due to ascribing the apparent features of objects to the objects themselves. The very existence of future metaphysics, Kant argued, would require a shift in perspective from the object to the spectator - a shift from objects to the form of our cognitive faculty.

The claim of Kant's Copernican shift is the claim that objects of experience must conform to the form of our cognitive faculty. This conformity involves multiple levels. Some levels are constitutive of experience. These include space, time, and what Kant calls the mathematical categories (the categories of quality and quantity). Other levels are not constitutive of experience, but rather regulate experience. This is the case with what Kant calls the dynamical catego- 
ries (the categories of relation and modality). My focus in this section is on those categories that are constitutive of experience. My claim is that on Kant's view, these constitutive categories are prior conditions for perception.

My account here is only a portion of the much larger story of Kant's Copernican shift. While his central point is that objects of experience must conform to our cognitive faculty (on multiple levels), it is important that on his view our cognitive faculty has a telos. Objects of experience conform to our cognitive faculty for the end of producing a body of knowledge. In this section, when I give an account of the role of constitutive categories in perceptual experience, this is an account of just one level at which objects of experience conform to our cognitive faculty. Each of these levels, however, is part of a larger operation, one whose end is the production of a body of knowledge.

At first glance, it seems obvious that perception requires a priori concepts for Kant. After all, one central thesis of Kant's Copernican shift is that objects of experience conform to our concepts, and not the other way around. Put this together with a major theme in the first Critique - that the categories are conditions of possible experience (CPR A95-96, B199) - and this specifies the role of the categories with respect to experience. They are not derived from it, as empirical concepts are, but rather they precede it. They are prior conditions for the very possibility of experience. As Kant puts it, there is a necessary agreement of experience with a priori concepts because those concepts make experience possible (CPR B166).

Since Kant says that the categories are conditions of possible experience, at first glance this seems to show that possession of the categories is a prior condition for perception. In fact, it does not show this conclusively. Although Kant clearly states that the categories are required for experience, or Erfahrung, he regularly uses the term Erfahrung to mean empirical knowledge. 
As he writes, the categories serve for "the possibility of empirical knowledge; and such knowledge is what we entitle experience [Erfahrung]" (CPR B147). So, at least in some places, Kant treats Erfahrung as a cognitive term, a term meaning "empirical knowledge."

When Kant claims that possession of the categories is a prior condition for experience, if experience is strictly a cognitive term, then he may just be saying that possession of the categories is a prior condition for empirical knowledge. If this is right, then just because possessing them is necessary for empirical knowledge, it does not follow that their possession is necessary for what we would think of as perception. It just follows that possessing them is necessary for what we would think of as cognition.

The same interpretive problem applies to Kant's Copernican shift. One of Kant's theses was that our basic concepts do not conform to objects of experience. Rather, objects of experience conform to our basic concepts (CPR Bxvii). However, if experience [Erfahrung] is just a cognitive term, then he may just be claiming that in cognition objects conform to our basic concepts. If it is just a cognitive term, then his claim may not apply to perception.

\subsection{A Way Forward}

We need a new argument in order to show that concepts play a necessary role in perception for Kant. Hannah Ginsborg offers one such approach. Ginsborg worries that if Kant's view reduces to the claim that a priori concepts are necessary for empirical knowledge, then his view faces the threat of triviality (2006b, p. 62). In the face of this, Ginsborg's strategy is to excavate a second notion of experience in addition to the first. This second notion is more like our ordinary empiricist notion of experience, and Ginsborg argues that Kant holds that concepts are necessary for this ordinary empiricist notion of experience as well. Ginsborg attempts to preserve the radical nature of Kant's view by holding that, for him, the categories are necessary not just for em- 
pirical knowledge, but for experience (in the ordinary empiricist sense of the term) as well. The looming difficulty for her is to show that Kant holds a unified and consistent account of experience, given that on her interpretation he holds two distinct notions of experience.

I suggest a new strategy, which I will sketch in the next part of the paper. Clearly, the conceptualist will need to fill in the details at much greater length than I do. But what I want to offer is a novel path that conceptualists can take. They can show that concepts play a necessary role in perception for Kant by appealing to Kant's notion of appearance [Erscheinung]. While "experience" means "empirical knowledge" (at least in some passages), "appearance" is not strictly a cognitive term. For one, it carries a connotation that is closer to what we normally think of as experience, almost a phenomenological connotation. Appearances appear [erscheinen] to us (CPR B69).

\subsection{Appearances}

What exactly are appearances? To start, appearances are mind-dependent entities. For example, Kant writes that appearances "cannot exist in themselves, but only in us" (CPR B59). This is not necessarily to say that appearances are mental entities. It is to say that appearances involve a relation between a subject and an object. Kant puts it more explicitly when he writes, "[A]ppearances do not exist in themselves, but only relative to the subject in which, so far as it has senses, they inhere..." (CPR B164).

A shadow cannot occur without something that casts it. Similarly, an appearance cannot occur without some thing of which it is an appearance. It is an "absurd conclusion," Kant says, "that there can be appearance without anything that appears" (CPR Bxxvi). After all, as he puts it, it follows from the very concept of an appearance that "something which is not in itself ap- 
pearance must correspond to it" (CPR A251). Simply put, an appearance, according to the meaning of term, depends on some object of which it is an appearance.

Let me note two points here. First, Kant is able to appeal to the ordinary meaning of the term "appearance" in explaining what he means by the term. For instance, he rules out conclusions that conflict with the ordinary meaning of appearance (CPR Bxxvi). He accepts conclusions that follow from the very concept of appearance (CPR A251). Second, since an appearance depends on some object of which it is an appearance, it follows that hallucinations do not count as appearances. Since an appearance depends on some object of which it is an appearance, and a hallucination does not depend on such an object, hallucinations are not appearances.

So far, I have claimed that an appearance requires some thing of which it is an appearance. But an appearance is more than this. It also requires the existence of a subject to which it appears. The property of being an appearance is like the property of being a brother. Being a brother is instantiated only given the existence of two things. First, a male must exist. Second, that male must have a sibling. Similarly, something is an appearance only given the existence of two things. First, there must be an object that it is an appearance of. Second, there must be a subject to which it appears.

One condition of something's being an appearance, then, is that there is some subject to which it appears. What I want to suggest is that this condition depends on a third condition. The initial condition can be met only if the subject possesses specific a priori concepts. So, an appearance can appear to a subject only if that subject possesses specific a priori concepts. My reason for this last claim is textual.

In a passage on the understanding (the faculty of cognition), Kant writes, "In the understanding there are then pure a priori modes of knowledge.... These are the categories, that is, the 
pure concepts of understanding... All appearances, as data for a possible experience, are subject to this understanding" (CPR A119). In short, the categories apply to all possible appearances. In the next section, I show specifically how the categories of quantity apply to them.

\subsection{The Categories of Quantity}

Consider the following skeptical worry. It could be the case that our appearances are unlawful. As humans, we could be saddled with "a melee of appearances" [ein Gewüle von Erscheinungen $]$ (CPR A111). Our appearances could be "mere ruleless heaps" [blo $\beta$ regellose Haufen] (CPR A121). As Kant puts it:

Appearances might very well be so constituted that the understanding should not find them to be in accordance with the conditions of its unity. Everything might be in such confusion that, for instance, in the series of appearances nothing presented itself which might yield a rule of synthesis and so answer to the concept of cause and effect. This concept would then be altogether empty, null, and meaningless. (CPR B123)

As Henry Allison points out, one of Kant's major concerns "is to exorcize this specter," and his goal "is to prove that everything given to the mind in accordance with its forms of sensibility, that is, all appearances, which includes everything that could possibly become an object of empirical consciousness, must be subject to the conditions of this unity, and therefore to the categories..." (2001, pp. 37-38). While it could have been the case that our appearances were unlawful, our appearances in fact have order. They conform to forms of our mind: to space, time, and the categories. This is the case not just for those appearances that we turn into knowledge. As Ginsborg puts it, "[T]he objective validity of the categories depends on their having a role to play, not just in explicit judgment, but also in our perceptual apprehension of the objects about which we judge" (2008, p. 70). Possession of the categories is a prior condition for all appearances.

Kant gives the example of perceiving a house (CPR B162). The categories of quantity (unity, plurality, totality) are operative not just for making a judgment about the house, but also 
in the very perception of the house itself. As Allison writes, "[I]t is not a matter of subsuming an object that one takes to be a house under the category of substance, but rather of a category functioning as a "rule of apprehension" (2004, p. 196). In our perception of a house, we do not just place the object of our perception under a concept - the concept of a house. The appearance of the house is not just a precondition for classifying that appearance as a house. Rather, the appearance is an end result of a prior classification. Concepts play a role in the very perceptual apprehension of the house itself. Specifically, the categories of quantity are operative.

Consider the example of a melody. Plausibly, when you perceive a melody, you do not just perceive the individual notes. You perceive the notes as being part of a unified whole. Similarly, on Kant's view, when you perceive a house, you perceive the parts of the house as parts of a unified whole. A melody consists of notes, which, over time, make up a temporal whole. A house consists of parts, which, over space, make up a spatial whole. In both cases, the perception of the parts makes the perception of the whole possible (see CPR B203). As with a melody, the house is a unified whole composed of a totality of parts. The concepts of quantity (unity, plurality, and totality) are operative in its perception.

The perception of a house is simply the example that Kant uses. However, he intends his point to apply to the perception of physical objects in general (see Griffith, 2010, p. 22). Kant writes, "[A]ll possible perceptions [Wahrnehmungen], and therefore everything that can come to empirical consciousness, that is, all appearances of nature, must, so far as their connection is concerned, be subject to the categories" (CPR B164-65).

Kant's account of the categories of quantity is an important feature of his Copernican shift. One thesis behind the shift was the claim that concepts do not conform to objects, but rather objects conform to our basic concepts. On Kant's view, the concepts of quantity (unity, 
plurality, and totality) provide a case in point. His claim is that the categories of quantity do not conform to objects. Rather, objects conform to them. Those concepts are particular instances of Kant's Copernican shift. They are concepts to which objects of experience conform. Like space and time, for Kant, the categories of quantity are constitutive of appearances.

\section{Kant's Theory of Perception}

\subsection{The Argument for Kantian Conceptualism}

Does perception require a priori concepts for Kant? Recall that Kant holds that the categories are necessary not just for experience, but also for appearance. The categories apply to all possible appearances (CPR A119, B164-65). Passages in Kant indicate that appearances are subject to the categories. But it is also the case that Kant's anti-skeptical project works only if appearances are subject to the categories. The application of the categories to appearances ensures that we do not end up with a lawless "melee of appearances" (CPR A111).

We can concede to the nonconceptualists that experience [Erfahrung] is a cognitive notion for Kant. We can allow that experience [Erfahrung] means something like empirical knowledge. We can concede that when Kant claims that the categories are necessary for experience, this does not show that they are necessary for perception. We can allow all of this as long as we hold that appearance [Erscheinung] is not a cognitive term. Nonconceptualists cannot reply that Kant's claim about the role of the categories in appearance is restricted to the generation of empirical knowledge. As Ginsborg puts it, "[T]he objective validity of the categories depends on their having a role to play, not just in explicit judgment, but also in our perceptual apprehension of the objects about which we judge" (2008, p. 70).

Nonconceptualist interpreters of Kant cannot deny that appearance involves concepts 
without overcoming some serious textual hurdles. Kant claims that the categories apply to all possible appearances (CPR A119, B143). He blocks the possibility that appearances could have been "mere ruleless heaps" (CPR A121). Appearances have order because concepts play a role in perception.

On Kant's view, when you perceive a house (or any physical object), concepts are active not just in your classification of that object as a house, but also in the very perceptual apprehension of the house itself (CPR B162). When you perceive a house, you perceive the parts of the house as parts of a unified whole, just as when you perceive a melody, you perceive the notes as being part of a unified whole. The categories of quantity (unity, plurality, and totality) are operative in that process. The upshot, as Kant puts it, is that "all possible perceptions [Wahrnehmungen], and therefore everything that can come to empirical consciousness, that is, all appearances of nature, must, so far as their connection is concerned, be subject to the categories" (CPR B164$65)$.

If nonconceptualist interpreters are to maintain that perception is not subject to the categories, they need to deny that appearance is subject to the categories. Since they need to deny that appearance is subject to the categories, and since Kant himself holds that appearance is subject to the categories, the nonconceptualist interpretation of Kant fails. Kant is a conceptualist.

Let's take stock then. Kant's slogan "Intuitions without concepts are blind" does not imply Conceptualism, the view that perception requires concepts. Still, Nonconceptualism does not follow. Although Kant does not rule out intuitions without concepts, he does not endorse them. But even if he did endorse them, it would not follow that Kant is a nonconceptualist. After all, it could be that he allows intuitions without empirical concepts, but denies intuitions without a priori concepts. Next, I argued that Kant does in fact deny intuitions without a priori concepts. The 
categories are prior conditions for appearance and not just for knowledge. So the standard nonconceptualist reply — that Kant is restricting his claims to the generation of knowledge — fails.

I do not mean to gloss over the many challenges that remain for this conceptualist interpretation of Kant, especially textual challenges. One set of textual challenges include Kant's claims that "appearances can certainly be given in intuition independently of functions of the understanding" ( $C P R \mathrm{~B} 122)$, and that "intuition stands in no need whatsoever of the functions of thought" (CPR B123). I am not entirely sure what to say about such passages. I think one possible strategy is to argue that Kant has in mind a logical possibility and a logical necessity, rather than what is possible and necessary for human experience. So, the strategy would be to explain such passages as claiming that it is logically possible that appearances are given in intuition independently of functions of the understanding (although not possible for creatures like us). Similarly, it is not logically necessary that intuition requires the functions of thought (although it is necessary for creatures like us). This is a start, but much more would need to be said in order to solidify this conceptualist interpretation.

\subsection{Kant and Skepticism}

I said earlier that Kant is responding to a skeptical worry: the worry that appearances could be "mere ruleless heaps" (CPR A121), leaving us with "a melee of appearances" $(C P R$ A111). The traditional mistake that fueled this worry was the idea that appearance comes to us raw and unprocessed. According to this view, you have an appearance, and then you classify it in some way. It is right that classification occurs posterior to appearance. But it is a fallacy to assume that because it occurs posterior to appearance, it occurs only posterior to appearance (see Laurence and Margolis, forthcoming). The traditional mistake is to think our concepts operate only after you have an image in your appearance. 
In cases of beliefs, sometimes a conceptual state reconceptualizes another conceptual state. Suppose that you are looking at a bird in a tree. You believe that it has a long beak and pear-shaped body. You think about what kind of bird it is. Then you form the belief, based on your prior belief, that the bird is a wren. Your belief that the bird is a wren is a conceptual state. But it would be a fallacy to think that just because that belief is conceptual, the prior belief, from which that belief is formed, is not itself conceptual.

Kant accepts that classification occurs posterior to appearance. Our empirical concepts classify appearances posterior to appearance. When you look at a house and form the judgment that the object is a house, for instance, you employ your empirical concepts of an object and a house. All this is consistent with the traditional view. But what Kant's view adds is that this conceptualization is actually a reconceptualization, not of another belief (as in the wren case), but of your appearance. The house appears to you only after the appearance is structured by the categories.

Kant's big move then is to say that appearances are already processed. They do not come to us raw and unprocessed. Once you have that image in appearance, it has already been classified, and just because posterior classification occurs, it does not follow that prior classification does not occur.

\subsection{A Reply to the Argument against State Conceptualism}

I now want to turn to the contemporary debate between conceptualists and nonconceptualists, and specifically to a technical distinction between two different versions of Nonconceptualism.

Perceptions have content, just as newspaper stories or television news reports do (see Siegel, 2011, section two, and Siegel, 2010, p. 28). They purport to represent the way things are, 
and do so accurately or inaccurately. Suppose a newspaper story reports on the events of a bank robbery, stating for instance that the robber was six feet tall and carried a gun. The content of the story is accurate or inaccurate. It accurately represents the way things are if the robber actually was six feet tall and actually carried a gun. Otherwise, it represents inaccurately. A television news report might show a surveillance video of the robbery. The video purports to represent the events as well, showing for instance that the thief stumbled as he exited the bank. Like the newspaper report, the video has content. It purports to represent the way things are, and it does so accurately or inaccurately. If the thief stumbled as he exited the bank, then the content of the video is accurate. If not, then the content is inaccurate.

Perceptions also have content. A bystander who observes the thief during the robbery sees that the thief's hair is brown. His perception represents the world in a particular way. The content of his perception is accurate if the thief's hair at that time was indeed brown. We can tell a similar story about beliefs. Beliefs represent the world in a particular way, and do so accurately or inaccurately. The bystander sees that the thief's hair is brown and forms the belief that the thief's hair is brown. That belief has content. If the thief's hair is brown, it is accurate. If not, it is inaccurate.

The notion of content motivates a distinction between two different versions of Nonconceptualism: Content Nonconceptualism and State Nonconceptualism. According to Content Nonconceptualism, the content of perception is different in kind from the content of beliefs (see Heck, 2000, p. 485, and Speaks, 2005, pp. 359-62). A content nonconceptualist typically holds that perceptual content is fundamentally imagistic, while belief content is fundamentally linguistic. Christopher Peacocke, for instance, argues that perceptual content is imagistic. On his view, a subject's perceptual content consists in a set of axes with its origin at the subject's center of 
gravity, where for each point, we "specify whether there is a surface there, and if so what texture, hue, saturation, brightness and temperature it has at that point, together with its degree of solidity" (2003, p. 108). Like Peacocke, content nonconceptualists often hold that perceptual content is imagistic in kind, and they contrast perceptual content with belief content, which they take to be linguistic in kind. According to proponents of this view, while beliefs represent properties that are articulable in terms of concepts (due to their linguistic structure), perception represents properties that are not articulable in terms of concepts (due to their imagistic structure). Due to a fundamental difference in kind, the argument goes, perceptual states cannot in principle be conceptual.

According to State Nonconceptualism, on the other hand, the content of perception has the same kind of content as the content of belief (both have a linguistic structure), but the states are different. On this view, a subject, $S$, is in a nonconceptual state if $S$ is in a state without possessing the concepts that articulate its content. According to this account, a perceptual state may be a nonconceptual state currently, even though there is no principled reason why it could not be a conceptual state. If $S$ has a perception of a shiny ball, for instance, but lacks the concept of shininess, then $S$ is in a nonconceptual perceptual state. But if she acquired that concept, then she would be in a conceptual perceptual state.

It is invalid to infer nonconceptual content from a nonconceptual state (see Speaks, 2005, p. 361). Just because $S$ is in a perceptual state without possessing the concepts for that content, it does not follow that the content itself is nonconceptual. The content could still be conceptually articulable even if $S$ lacks the concepts to articulate that content. If $S$ has a perception of a shiny ball, but lacks the concept of shininess, then $S$ is in a nonconceptual state, but the content if that state is still articulable in terms of the concept of shininess. 
Does the same hold true for conceptual states? That is, if $S$ is in a conceptual state, does it follow that the content of that state is conceptual? If not, then this would be problematic for the view I am suggesting Kant holds. Kant's version of Conceptualism, in the way that I have formulated it, is a claim about states. $S$ can be in a perceptual state only if she possesses the relevant concepts. If a state's being conceptual does not imply that its content is conceptual, then that thesis does not actually make a claim about conceptual content. Since the debate is typically cast as a debate about conceptual content, and not just conceptual states, Kant's view would be of limited worth.

I accept the reason for why a nonconceptual state does not imply nonconceptual content. However, I do not think that an analogous reason denies the inference from a conceptual state to conceptual content. A nonconceptual state does not imply nonconceptual content for the following reason: just because $S$ cannot articulate the content, it does not follow that the content is inarticulable in principle. Consider the analogous argument applied to Conceptualism. Just because $S$ can articulate the content, it does not follow that the content is articulable in principle. This argument is invalid. The very fact that you can articulate the content does show that it is articulable. If you have a perception of a shiny ball, and can articulate that the ball is shiny, then the content of that perception is articulable. So the standard reason for why a nonconceptual state does not imply nonconceptual content fails to show that a conceptual state does not imply conceptual content.

\section{Conclusion}

This paper has focused on two rival interpretations of Kant, but I want to end by pointing out a premise shared by everyone in the debate. One thing that both sides agree on is that, for Kant, there is no empirical knowledge without empirical concepts. Nonconceptualist interpreters 
assume this in their response to conceptualist interpreters. Nonconceptualist interpreters argue that "intuitions without concepts are blind" means only that intuitions without empirical concepts cannot yield empirical knowledge. They argue that the slogan says nothing about perception, but is actually about what is required for empirical knowledge. But this response itself assumes that empirical knowledge requires empirical concepts. So, in preserving the possibility of intuitions without empirical concepts, they accept that empirical knowledge requires empirical concepts.

The thesis that empirical knowledge requires concepts is intuitive. One might deny that perception requires concepts. However, it seems very likely that beliefs require concepts. For instance, it seems implausible that one could have a belief that the bird is a wren without having the concept of a wren. Given that empirical knowledge requires belief, empirical knowledge requires concept possession. One cannot have the empirical knowledge that the bird is a wren without having the concept of a wren. So, empirical knowledge requires concept possession.

For any claim that Kant makes about the impossibility of intuition without concepts, nonconceptualists can claim that we can restrict that claim to the role of intuitions in the production of knowledge. Importantly, though, this knowledge restriction strategy shares an assumption with conceptualists, namely, that perceptual knowledge requires empirical concepts, even if perception does not. So both sides of the debate agree that for Kant, empirical knowledge requires empirical concepts.

Let's take stock. Kant championed a Copernican shift for philosophy according to which objects of experience conform to the form of our cognitive faculty rather than the other way around. One central tenet of Kant's Copernican shift is that perceptual objects conform to some of our basic concepts. In this paper, I defended this central tenet as an interpretation of Kant (several scholars have challenged it in the last decade). I argued that despite these recent attempts 
to show otherwise, perception requires concepts for Kant. On my reading, objects of perception conform to some of our basic concepts, but there is little reason to think that other (non-basic) concepts are required for perception (although they are required for perceptual knowledge). ${ }^{5}$

\footnotetext{
${ }^{5}$ Thanks to Paul Franks, Mohan Matthen, Diana Raffman, Charles Siewert, Owen Ware, Aaron Griffith, Anthony Bruno, and two anonymous referees.
} 


\section{References}

Allais, Lucy (2009). “Kant, Non-Conceptual Content and the Representation of Space.” Journal of the History of Philosophy, vol. 47, no. 3, 383-413.

Allison, Henry (2001). Kant's Theory of Taste: a Reading of the Critique of Aesthetic Judgment. Cambridge: Cambridge University Press.

— (2004). Kant's Transcendental Idealism. New Haven: Yale University Press.

Crane, Tim (2008). “Is Perception a Propositional Attitude?” Philosophical Quarterly, 59(236): 452-469.

Ginsborg, Hannah (2006a). "Empirical Concepts and the Content of Experience." European Journal of Philosophy, 14(3), 349-372.

— (2006b). "Kant and the Problem of Experience." Philosophical Topics, 34: 59-106.

_ (2008). “Was Kant a Nonconceptualist?” Philosophical Studies, 137: 65-77.

Gram, Moltke S. (1982). “The Sense of a Kantian Intuition.” In Gram (Ed.), Interpreting Kant. Iowa City: University of Iowa Press.

Griffith, Aaron (2010). "Perception and the Categories: A Conceptualist Reading of Kant's Critique of Pure Reason." European Journal of Philosophy, 18(2), 1-30.

Hanna, Robert (2005). "Kant and Non-Conceptual Content.” European Journal of Philosophy, 13: $247-290$.

_ (2008). “Kantian Nonconceptualism.” Philosophical Studies, 137: 41-64.

Heck, R. G. (2000).“Nonconceptual Content and the "Space of Reasons."” The Philosophical Review, vol. 109, no. 4, 483-523. 
Kant, Immanuel (1992). “The False Subtlety of the Four Syllogistic Figures," In Immanuel Kant: Theoretical Philosophy, trans. D. Walford and R. Meerbote. Cambridge: Cam bridge University Press, pp. 85-105. (Original Work Published 1755-1770).

_ (2003). Critique of Pure Reason. (Norman Kemp Smith, Trans.). New York:

Palgrave MacMillan. (Original Work Published 1787).

— (1956). Kritik der reinen Vernunft. Hamburg: Felix Meiner. (Original Work Published 1787).

— (2006) Anthropology from a pragmatic point of view. In Robert B. Louden, and Manfred Kuehn. Cambridge: Cambridge University Press.

__ (1992). “Jäsche Logic.” In Immanuel Kant: Lectures on Logic. (J.M. Young, Trans.). Cambridge: Cambridge University Press. (Original Work Published 1800). Laurence, Stephen, and Margolis, Eric (forthcoming). "The Scope of the Conceptual.” In E. Margolis, R. Samuels, and S. Stich (Eds.), The Oxford Handbook of Philosophy and Cognitive Science. Oxford: Oxford University Press.

McDowell, John (1994). Mind and World. Cambridge: Harvard University Press.

_ (2008). "Avoiding the Myth of the Given.” In J. Lindgaard (Ed.), John McDowell: Experience, Norm, and Nature. Oxford: Blackwell.

McLear, Colin (2011). “Kant on Animal Consciousness.” Philosophers' Imprint. Volume 11, No. 15 .

Peacocke, Christopher (2003). "Scenarios, Concepts, and Perception.” In Y. Gunther (Ed.), Essays on Nonconceptual Content. Cambridge: MIT Press.

Rohs, P. (2001). “Bezieht sich nach Kant die Anschauung unmittelbar auf Gegenstände?” In Akten des IX. Internationalen Kant-Kongresses, vol. 2. Berlin: de Gruyter. 
Siegel, Susanna (2010). The Contents of Visual Experience. Oxford: Oxford University Press.

Siegel, Susanna (2011). "The Contents of Perception.” In E. N. Zalta (Ed.), The Stanford Encyclopedia of Philosophy, $\mathrm{URL}=<\mathrm{http}: /$ plato.stanford.edu/archives/spr2011/entries/perception-contents/ $>$.

Smith, A. D. (2002). The Problem of Perception. Cambridge: Harvard University Press.

Speaks, Jeff (2005). “Is There a Problem About Nonconceptual Content?” The Philosophical Review, 114, 359-398.

Wenzel, Christian Helmut (2005). “Spielen nach Kant die Kategorien schon bei der Wahrnehmung eine Rolle? Peter Rohs und John McDowell.” Kant-Studien, 96, 407-426. 